\title{
Postoperative cognitive dysfunction after inhalational anesthesia in elderly patients undergoing major surgery: the influence of anesthetic technique, cerebral injury and systemic inflammation
}

\author{
Yong Qiao ${ }^{1}$, Hao Feng ${ }^{1}$, Tao Zhao ${ }^{2}$, Heng Yan ${ }^{1}$, He Zhang ${ }^{1}$ and Xin Zhao ${ }^{1 *}$
}

\begin{abstract}
Background: Elderly patients are reportedly at higher risk of postoperative cognitive dysfunction (POCD) after inhalational anesthesia with sevoflurane. We hypothesized that the incidence of POCD would be higher in elderly patients undergoing major surgery under inhalational rather than intravenous anesthesia. We also measured plasma S-100 $\beta$ protein concentration as a biomarker of central nervous system injury, and plasma interleukin (IL)-6 and tumor necrosis factor (TNF)-a concentrations to judge the contribution of systemic inflammation to POCD.

Methods: Ninety patients aged 65-75 years scheduled for resection of an esophageal carcinoma were randomly assigned to one of three groups $(n=30)$ as follows: a group receiving sevoflurane anesthesia (Group S); a group receiving preoperative methylprednisolone before sevoflurane anesthesia (Group S + MP); and a control group maintained with intravenous propofol (Group C). The mini-mental state examination (MMSE) and Montreal cognitive assessment (MoCA) were used to measure patients' cognitive function the day before surgery, and on the first, third and seventh postoperative days. The plasma concentrations of TNF- $a$, IL- 6 and S-100 $\beta$ protein were measured 10 min before anesthesia, and on the first, third and seventh postoperative days.

Results: There were no significant differences in the demographic or clinical characteristics, or perioperative hemodynamic status, of the three groups. The MMSE and MoCA scores were significantly lower in Group $S$ than in the propofol control (Group C) and Group S + MP on the first, third and seventh postoperative days $(P<0.05)$. Throughout the first postoperative week the plasma concentrations of TNF-a, IL-6, and S-100 $\mathrm{B}$ protein were significantly elevated in Group $S$ compared with Group $C(P<0.05)$, but were significantly lower in Group $S+M P$ than Group $S(P<0.05)$.

Conclusions: The incidence of POCD was higher in elderly patients undergoing major surgery under inhalational anesthesia with sevoflurane than those maintained on intravenous propofol, and lower in elderly patients pro-treating with methylprednisolone. Furthermore, we found elevated plasma concentrations of S-100ß protein, TNF-a and IL-6 in those receiving sevoflurane anesthesia.
\end{abstract}

Trial registration: ChiCTR-IOR-15007007 (02-09-2015).

Keywords: POCD, Sevoflurane inhalation anesthesia, TNF-a, IL-6, S-100ß protein

\footnotetext{
*Correspondence: lujnzx@sohu.com

'Department of Anesthesiology, the Second Affiliated Hospital of Shandong University, Ji'nan, Shandong 250033, China

Full list of author information is available at the end of the article
} 


\section{Background}

Postoperative cognitive dysfunction (POCD) is characterized by progressive hypomnesia, personality change or deterioration in cognitive function after surgery [1]. The incidence of POCD is rising steadily in patients undergoing general anesthesia $[2,3]$. Age is the main risk factor for POCD, and although it is well recognized that the incidence of POCD is higher in the elderly [4], particularly those undergoing sevoflurane anesthesia [5], the mechanism is not fully understood.

There have been several reports that central nervous system inflammation provoked by anesthesia and surgery plays an important role in the pathogenesis of POCD [6]. Anesthesia and surgery have been shown to increase the brain concentration of interleukin (IL)-6, leading to neuronal apoptosis [7], and to provoke the release of the pro-inflammatory cytokine tumor necrosis factor (TNF)- $\alpha$ [8]. S-100 $\beta$ protein is an acidic calcium-binding protein found in the central nervous system, and when detected in the systemic circulation is considered a biomarker of acute brain injury $[8,9]$.

We undertook a randomized clinical trial to establish whether TNF- $\alpha$, IL- 6 or S-100 $\beta$ might play a role in the pathogenesis of POCD in elderly patients undergoing resection of an esophageal carcinoma under sevoflurane anesthesia with or without preoperative methylprednisolone, or under total intravenous anesthesia with propofol. Identifying a relationship between
Table 1 Clinical characteristics of patients

\begin{tabular}{lcccc}
\hline & Group C & Group S & Group S + MP & $P$-Value \\
\hline $\begin{array}{lcccc}\text { Gender (n) } \\
\text { Male/Female }\end{array}$ & $21 / 9$ & $22 / 8$ & $21 / 9$ & $0.832^{*}$ \\
Age (yr) & $68 \pm 2$ & $68 \pm 3$ & $69 \pm 3$ & 0.705 \\
$\begin{array}{l}\text { Body Mass } \\
\text { Index (BMI) }\end{array}$ & $24.41 \pm 1.52$ & $23.65 \pm 1.14$ & $24.24 \pm 3.19$ & 0.831 \\
$\begin{array}{l}\text { Preoperative } \\
\text { MMSE Scores }\end{array}$ & $28.62 \pm 1.14$ & $27.83 \pm 1.79$ & $27.45 \pm 1.14$ & 0.408 \\
$\begin{array}{l}\text { Duration of } \\
\text { Surgery (min) }\end{array}$ & $130 \pm 5$ & $128 \pm 8$ & $130 \pm 5$ & 0.786 \\
\hline
\end{tabular}

Data are given as mean $\pm \mathrm{SD}$. ${ }^{*}$ Fisher exact test

the serum concentrations of these pro-inflammatory cytokines and markers of cerebral injury would be an important step towards establishing strategies for the prevention of POCD.

\section{Methods}

The study design was a prospective, double blind, randomized, controlled trial. It was conducted at the Second Affiliated Hospital of Shandong University, after approval had been obtained from the ethics committee of the Second Affiliated Hospital of Shandong University (IRB protocol number: SDUEY20121118). Informed consent was obtained from each participant.

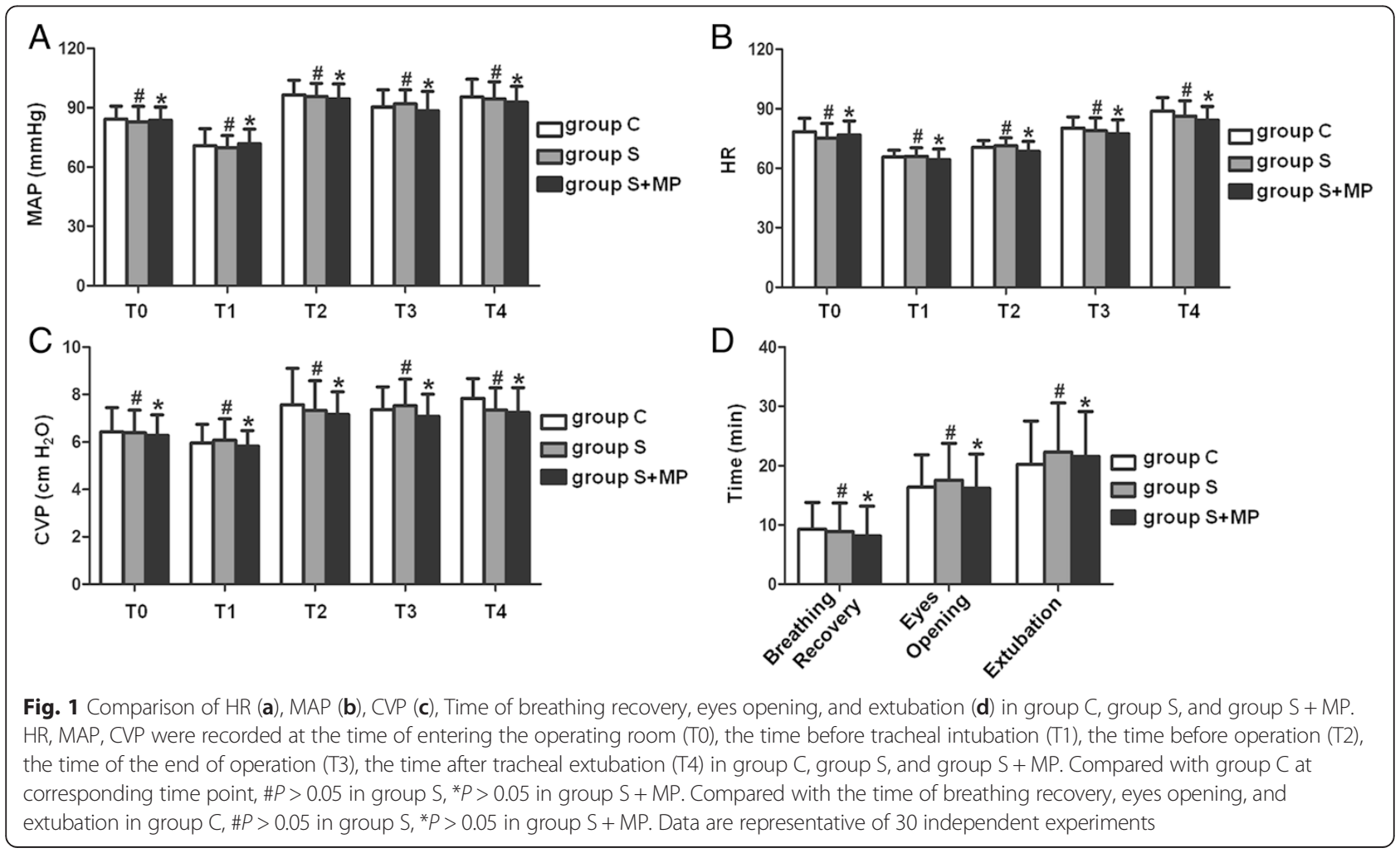


Table 2 Emergence from anaesthesia

\begin{tabular}{lrrrr}
\hline & Group C & \multicolumn{1}{c}{ Group S } & Group S + MP & $P$-Value \\
\hline Breathing recovery & $9.2 \pm 4.5$ & $8.9 \pm 4.2$ & $8.1 \pm 5.0$ & 0.918 \\
Eyes opening & $16.4 \pm 5.5$ & $17.6 \pm 6.2$ & $16.2 \pm 5.7$ & 0.912 \\
Extubation & $20.2 \pm 7.2$ & $22.2 \pm 8.1$ & $21.6 \pm 7.5$ & 0.914 \\
\hline
\end{tabular}

All times are given as mean \pm SD

\section{Patients}

Ninety patients aged between 65 and 75 years undergoing esophageal carcinoma resection between January 2013 and December 2014 were enrolled. Patients were randomly assigned to one of three groups $(n=30)$ as follows: a group receiving sevoflurane anesthesia (Group S); a group receiving sevoflurane anesthesia after preoperative treatment with methylprednisolone (Group $\mathrm{S}+\mathrm{MP}$ ); and a control group of patients receiving intravenous propofol anesthesia (Group C).

The inclusion criteria were: American Society of Anesthesiologists (ASA) physical status I, II or III; a sufficient level of education to be capable of completing neuropsychological tests; a pre-operative mini mental state examination (MMSE) score $\geq 23$; no evidence of cardiovascular, respiratory or central nervous system disease; normal renal and hepatic function; no serious hearing or visual impairment; absence of a history of benzodiazepine or antidepressant use, alcohol or cigarette misuse or drug dependence; and no contraindication to propofol or inhalational anesthesia.
Table 3 Comparison of the levels of MMSE in group C, group S, and group S + MP

\begin{tabular}{lllccc}
\hline & Group C & Group S & Group S + MP & P1-Value & P2-Value \\
\hline Ts & $28.16 \pm 1.60$ & $27.83 \pm 1.94$ & $28.33 \pm 1.21$ & 0.725 & 0.599 \\
Tb & $22.50 \pm 2.26$ & $19.17 \pm 2.14$ & $22.43 \pm 2.43$ & 0.023 & 0.023 \\
Tc & $24.67 \pm 3.67$ & $19.33 \pm 3.83$ & $25.67 \pm 2.34$ & 0.015 & 0.005 \\
Td & $26.67 \pm 3.67$ & $20.33 \pm 3.39$ & $27.33 \pm 4.37$ & 0.012 & 0.006 \\
\hline
\end{tabular}

Data are given as mean \pm SD. P1-Value, group S versus group C (LSD). P2-Value, group $\mathrm{S}+\mathrm{MP}$ versus group $\mathrm{S}(\mathrm{LSD})$

\section{Patient management}

Anesthesia was managed according to a standardized protocol that was identical for each group. Patients had fasted for $8 \mathrm{~h}$ and abstained from water for $4 \mathrm{~h}$ preoperatively. Arterial blood pressure, heart rate (HR), the electrocardiogram, peripheral blood oxygen saturation, bispectral index (BIS), end tidal $\mathrm{CO}_{2}\left(\mathrm{P}_{\mathrm{ET}} \mathrm{CO}_{2}\right)$ and internal jugular central venous pressure were monitored in the operating room and recorded every $5 \mathrm{~min}$.

Following $3 \mathrm{~min}$ of pre-oxygenation (with $100 \% \mathrm{O}_{2}$ ), anesthesia was induced by means of a single slow intravenous injection of midazolam (2-3 mg), etomidate $(0.3 \mathrm{mg} / \mathrm{kg})$ and an infusion of sufentanil $(0.4 \mu \mathrm{g} / \mathrm{kg})$. Tracheal intubation was facilitated with cisatracurium besylate $(0.3 \mathrm{mg} / \mathrm{kg})$. A left-sided double-lumen Robertshaw endobronchial tube (diameter Fr 35-39) was positioned using a laryngoscope.

Mechanical ventilation was initiated with a tidal volume of $7 \mathrm{ml} / \mathrm{kg}$, a respiratory rate of $12 / \mathrm{min}$, a positive end expiratory pressure of $5 \mathrm{cmH}_{2} \mathrm{O}$ and inspiratory-
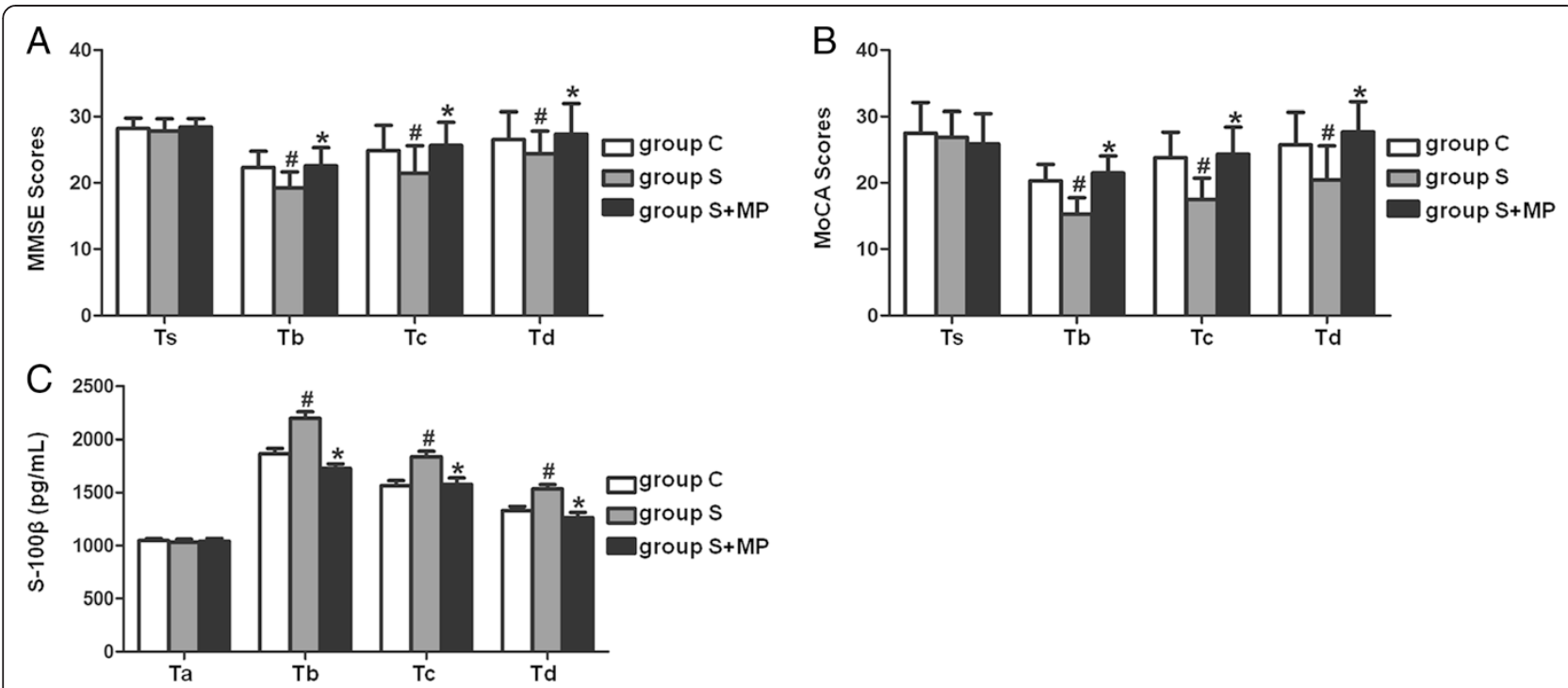

Fig. 2 Comparison of MMSE and MoCA scores, S-100 $\beta$ protein level in group C, group S, and group S + MP. MMSE and MoCA scores were used to assess the cognitive function at the day before operation (Ts), the first (Tb), third (Tc), and seventh (Td) day after operation, and S-100 $\beta$ protein level was used to reflect the level of brain injury at 10 min before anesthesia (Ta), the first (Tb), third (Tc), and seventh (Td) day after operation in different groups. a and b: MMSE and MoCA scores in different groups. Compared with Group C at Tb, Tc, and Td, \#P <0.05 in group S; Compared with Group S at Tb, Tc, and Td, *P <0.05 in group S + MP. c: S-100 $\beta$ protein level in different groups. Compared with Group C at Tb, Tc, and Td, $\# P<0.05$ in group $\mathrm{S}$; Compared with Group $\mathrm{S}$ at $\mathrm{Tb}, \mathrm{T}$, and $\mathrm{Td}$, $* P<0.05$ in group $\mathrm{S}+\mathrm{MP}$. Data are representative of 30 independent experiments 
Table 4 Comparison of the levels of MoCA in group C, group S, and group S + MP

\begin{tabular}{lllccc}
\hline & Group C & Group S & Group S + MP & P1-Value & P2-Value \\
\hline Ts & $27.55 \pm 4.58$ & $26.90 \pm 3.83$ & $25.95 \pm 2.61$ & 0.769 & 0.684 \\
Tb & $20.33 \pm 2.34$ & $15.33 \pm 2.58$ & $21.48 \pm 2.43$ & 0.003 & 0.001 \\
TC & $23.83 \pm 3.87$ & $17.83 \pm 2.99$ & $24.33 \pm 3.33$ & 0.008 & 0.005 \\
Td & $25.33 \pm 4.89$ & $18.01 \pm 4.15$ & $27.67 \pm 4.41$ & 0.013 & 0.002 \\
\hline
\end{tabular}

Data are given as mean \pm SD. P1-Value, group S versus group C (LSD). P2-Value, group $S+M P$ versus group $S$ (LSD)

expiratory ratio of $1: 2$ to maintain $\mathrm{P}_{\mathrm{ET}} \mathrm{CO}_{2}$ in the range 35-40 mmHg. Oxygen flow rate was set at $2 \mathrm{l} / \mathrm{min}$.

Anesthesia was maintained in Group $C$ by propofol administered by target controlled infusion (effect site concentration $4 \mathrm{ug} / \mathrm{ml}$ ) and 1 minimum alveolar concentration (MAC) sevoflurane in Groups $\mathrm{S}$ and group $\mathrm{S}+\mathrm{MP}$. Intravenous infusion of methylprednisolone $(10 \mathrm{mg} / \mathrm{kg})$ was administered 30 min before anesthesia to patients in Group $\mathrm{S}+\mathrm{MP}$. Maintenance of anesthesia was supplemented by an intravenous infusion of remifentanil (commenced at $0.15 \mu \mathrm{g} / \mathrm{kg} / \mathrm{min}$ and titrated according to clinical need). The sevoflurane or propofol was titrated on the basis of hemodynamic parameters (HR, systolic arterial blood pressure), to maintain BIS in the range 50-60, and if somatic (swallowing, movement) or autonomic signs (flushing, sweating, salivating) were evident. A 5-mg bolus of cisatracurium besylate was administered every $30 \mathrm{~min}$ according to clinical need. Sevoflurane and propofol were discontinued at the start of suturing.

Intravenous crystalloids were administered $(0.9 \% \mathrm{NaCl}$ solution supplemented by lactated Ringer's solution at a ratio of 3:1) at an infusion rate of $0.5-1.0 \mathrm{ml} / \mathrm{kg} / \mathrm{min}$ for 20-40 $\mathrm{min}$ followed by an infusion rate of $0.25 \mathrm{ml} / \mathrm{kg} \mathrm{min}$ to maintain a positive daily fluid balance and adequate urine output.

Postoperative analgesia (PCA: sufentanil $2 \mathrm{ug} / \mathrm{kg}$ ) was provided using a patient-controlled intravenous technique for the first $72 \mathrm{~h}$, with the following settings: $2 \mathrm{ml} / \mathrm{h}$ background infusion; $0.5-\mathrm{ml}$ bolus, and a $15-\mathrm{min}$ lockout.

Patients' demographic and basic clinical characteristics, fluid balance, blood loss, duration of surgery, duration of single lung ventilation, temperature, time taken for recovery of spontaneous breathing, eye opening on command and time taken for extubation were also recorded. We recorded HR, mean arterial pressure (MAP) and central venous pressure at five perioperative time points: on entering the operating room (T0); before tracheal intubation (T1); before surgery (T2); immediately after surgery (T3) and immediately after tracheal extubation (T4).

\section{Enzyme-linked immunosorbent assay (ELISA)}

Blood specimens were collected from the patients $10 \mathrm{~min}$ before anesthesia (Ta), and on the first (Tb), third (Tc), and seventh $(\mathrm{Td})$ postoperative days. Plasma was obtained by centrifugation at $4000 \times \mathrm{g}$ for $20 \mathrm{~min}$ at $4{ }^{\circ} \mathrm{C}$ and stored at $-80{ }^{\circ} \mathrm{C}$. The concentrations of IL-6, TNF- $\alpha$ and S100 $\beta$ protein were measured using an ELISA kit according to the manufacturer's instructions.

\section{Assessment of perioperative cognitive function}

The MMSE and Montreal Cognitive Assessment (MoCA) were used to assess cognitive function the day before surgery (Ts), and on the first (Tb), third (Tc) and seventh (Td) postoperative days. All data collectors had undergone standard training, and were blinded to the randomization status of the participants. The MMSE consists of tests of orientation (in time and place), memory (immediate and short-term), calculation, language (naming, repetition, listening and reading comprehension, writing), visual spatial awareness, concentration and attention, and is suitable for detecting more severe cognitive dysfunction. The MoCA tests visuospatial and executive function (alternate trail making test, copy the cube, clock drawing), language ability, attention and calculation, delayed recall and abstract thinking, and can detect milder cognitive dysfunction. Patients' cognitive function was evaluated by MoCA if the MMSE score equaled or exceeded 20.

\section{Statistical analysis}

Assays were performed in triplicate, and representative examples of at least one assay are shown. All data are expressed as mean \pm standard deviation (SD). Statistical differences were assessed using one-way analysis of variance (ANOVA) with the least significant difference (LSD) post hoc tests. A P value $<0.05$ was considered statistically significant. All statistical analyses were performed using the SPSS 19.0 statistics program for windows (SPSS, IBM, USA).

Table 5 Comparison of the levels of $S 100 \beta$ in group C, group $S$, and group $S+M P$

\begin{tabular}{llllcr}
\hline & Group C & Group S & Group S + MP & P1-Value & P2-Value \\
\hline Ta & $1043.42 \pm 20.73$ & $1028.45 \pm 28.73$ & $1038.61 \pm 26.65$ & 0.327 & 0.503 \\
$\mathrm{~Tb}$ & $1864.93 \pm 50.51$ & $2194.28 \pm 63.72$ & $1728.87 \pm 40.31$ & 0.000 & 0.000 \\
$\mathrm{Tc}$ & $1562.37 \pm 48.08$ & $1836.55 \pm 52.37$ & $1576.73 \pm 58.59$ & 0.000 & 0.000 \\
$\mathrm{Td}$ & $1328.83 \pm 38.22$ & $1531.60 \pm 42.83$ & $1261.50 \pm 50.15$ & 0.000 & 0.000
\end{tabular}

Data are given as mean \pm SD. P1-Value, group S versus group C (LSD). P2-Value, group S + MP versus group S (LSD) 

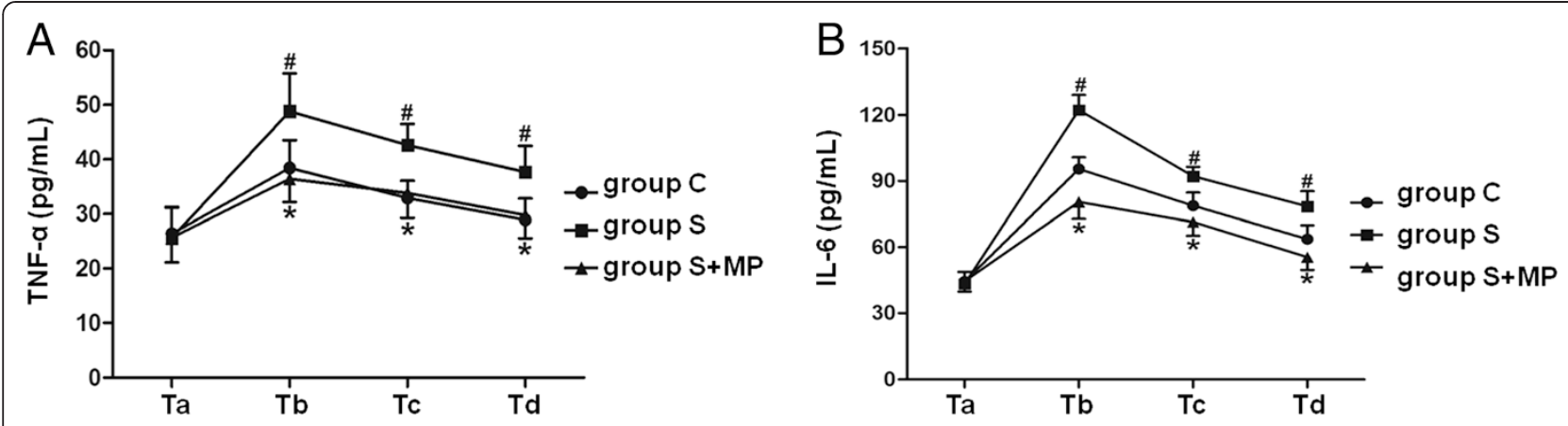

Fig. 3 Comparison of the levels of TNF-a, IL-6 in group C, group S, and group S+MP. The levels of TNF-a, IL-6 were used to reflect the systemic inflammatory response at 10 min before anesthesia (Ta), the first (Tb), third (Tc), and seventh (Td) day after operation in group C, group S, and group S + MP. a: the level of TNF-a in different groups. Compared with Group C at Tb, Tc, and Td, \#P<0.05 in group S; Compared with Group S at Tb, Tc, and Td, ${ }^{*} P<0.05$ in group S + MP. b: the level of IL-6 in different groups. Compared with Group C at Tb, Tc, and Td, \#P <0.05 in group S; Compared with Group $S$ at Tb, Tc, and $T d,{ }^{*} P<0.05$ in group $S+M P$. Data are representative of 30 independent experiments

\section{Results}

Participants' demographic and clinical characteristics There were no significant differences between the groups in terms of gender, age, body mass index (BMI) or preoperative MMSE scores (Table 1), nor were there significant differences in perioperative hemodynamic parameters (Fig. 1a, b, c), time to recovery of spontaneous breathing, emergence from anesthesia or time to extubation (Fig. 1d; Table 2).

\section{Cognitive function assessment and plasma S-100 $\beta$ concentration}

The MMSE and MoCA scores on the first, third and seventh postoperative days were significantly lower in Group $S$ than controls $(P<0.05$; Fig. $2 \mathrm{a}$, b; Tables 3 and 4$)$. Furthermore, the MMSE and MoCA scores on the first, third and seventh postoperative days were significantly higher in Group $S+M P$ than Group S $(P<0.05$; Fig. 2a, b; Tables 3 and 4). The concentration of plasma $S-100 \beta$ protein was significantly higher in Group $S$ than Group $C$ and Group $S$ $+\mathrm{MP}$ at all postoperative time points $(P<0.05$; Fig. $2 \mathrm{c}$; Table 5).

\section{Plasma IL- 6 and TNF-a concentrations}

The plasma concentrations of IL- 6 and TNF- $\alpha$ were significantly higher in Group S on the first, third and seventh

Table 6 Comparison of the levels of IL-6 in group C, group S, and group S + MP

\begin{tabular}{llrccc}
\hline & Group C & \multicolumn{1}{c}{ Group S } & Group S + MP & P1-Value & P2-Value \\
\hline Ta & $44.33 \pm 4.41$ & $43.25 \pm 5.40$ & $44.52 \pm 4.79$ & 0.707 & 0.664 \\
Tb & $95.40 \pm 5.31$ & $122.23 \pm 6.85$ & $80.48 \pm 7.71$ & 0.000 & 0.000 \\
Tc & $78.75 \pm 5.98$ & $92.11 \pm 4.26$ & $71.32 \pm 6.18$ & 0.001 & 0.000 \\
Td & $63.58 \pm 6.33$ & $78.43 \pm 6.95$ & $55.42 \pm 5.82$ & 0.001 & 0.000 \\
\hline
\end{tabular}

Data are given as mean \pm SD. P1-Value, group S versus group C (LSD). P2-Value, group $\mathrm{S}+\mathrm{MP}$ versus group $\mathrm{S}(\mathrm{LSD})$ postoperative days than controls $(P<0.05$; Fig. 3a, b; Tables 6 and 7), and were significantly lower in group $S$ than those in Group $\mathrm{S}+\mathrm{MP}(P<0.05$; Fig. 3a, b; Tables 6 and 7 ) at each time point.

\section{Discussion}

We found that the incidence of POCD in elderly patients undergoing major surgery was higher in those receiving sevoflurane general anesthesia than those receiving total intravenous anesthesia with propofol. We also found that methylprednisolone afforded a degree of neuroprotection in those receiving sevoflurane anesthesia, and that POCD was associated with elevated postoperative plasma concentrations of TNF- $\alpha$, IL-6 and S100ß protein.

Postoperative cognitive dysfunction may be manifest as impairment of working memory, long-term memory, information processing, attention or cognitive flexibility [10], adversely affecting quality of life, social independence and mortality [11]. It may persist for weeks or months, and may not resolve at all in a small proportion of those affected [12].

Inhalational anesthetic drugs are reported to promote neuronal apoptosis in animal models, leading to a decline in learning ability and memory after anesthesia [13-15]. Uemura et al. documented behavioral abnormalities in

Table 7 Comparison of the levels of TNF-a in group C, group S, and group S + MP

\begin{tabular}{lllccc}
\hline & Group C & Group S & Group S + MP & P1-Value & P2-Value \\
\hline Ta & $26.37 \pm 4.73$ & $25.65 \pm 5.62$ & $25.68 \pm 4.56$ & 0.807 & 0.991 \\
Tb & $38.41 \pm 5.13$ & $48.82 \pm 6.89$ & $36.43 \pm 4.27$ & 0.005 & 0.002 \\
Tc & $32.92 \pm 3.16$ & $42.63 \pm 3.87$ & $33.83 \pm 4.54$ & 0.001 & 0.001 \\
Td & $28.92 \pm 3.90$ & $37.65 \pm 4.84$ & $29.80 \pm 4.28$ & 0.003 & 0.007 \\
\hline
\end{tabular}

Data are given as mean \pm SD. P1-Value, group S versus group C (LSD). P2-Value, group S + MP versus group S (LSD) 
adult rats that had been exposed to halothane in utero [16]. Exposure to a low concentration of halothane or $\mathrm{N}_{2} \mathrm{O}$ reportedly causes visual impairment, and reduces instantaneous memory, and athletic and cognitive abilities [17]. Post-exposure cognitive function is also reportedly superior in patients anesthetized with intravenous propofol than those treated with sevoflurane [18].

Our findings are consistent with this body of research. We documented a substantial reduction in MMSE and MoCA scores in the first postoperative week in those exposed to sevoflurane rather than propofol. This suggests that sevoflurane increases the risk of POCD in elderly patients undergoing major surgery.

The presence of S100 $\beta$ protein in the systemic circulation is an indicator of central nervous system injury. With increasing age, ongoing demyelination leads to an increase in the plasma concentration and half-life of S-100 $\beta$ protein [19]. The physiological role of $S 100 \beta$ protein, which is produced by astrocytes, is to enhance interaction between neurons and glial cells [20]. An increased concentration of S100 $\beta$ protein is indicative of a severe brain injury [21]. We found that the plasma concentration of $S 100 \beta$ protein was significantly more elevated throughout the first postoperative week in those anesthetized with sevoflurane compared with those who received propofol. This suggests that plasma S100 $\beta$ protein concentration could be used as a biomarker of POCD.

In the elderly, POCD may persist for weeks or months after inhalational anesthesia and a small minority of patients is affected for longer; however, the pathophysiologic mechanisms are still not fully understood. Propofol is reported to inhibit the activation and release of inflammatory factors such as IL- 6 and TNF- $\alpha$ by astrocytes in the central nervous system [22, 23]. This implicates IL-6 and TNF- $\alpha$ in the pathogenesis of POCD caused by sevoflurane.

Interleukin-6 is an important regulator of synapse formation; a high local concentration of IL-6 is reported to inhibit synaptic function. Hippocampal neurogenesis in the dentate gyrus is reported to be decreased by $63 \%$ in adult transgenic rats that overexpress IL- 6 from their astrocytes [24]. Administration of a neutralizing antibody for IL-6 also significantly improves long-term potentiation (LTP) and spatial memory in rats. The influence of IL-6 on the generation of LTP, and its inhibitory effects on learning and memory, suggest it is likely to also play a role in POCD [25].

Tumor necrosis factor- $\alpha$ is a cell signaling protein involved in innate and specific immunity, and promotes the inflammatory response [26, 27]. Monocytes and macrophages activated by external stimuli release TNF- $\alpha$, which in turn promotes the release of other inflammatory mediators and pro-inflammatory cytokines such as IL-6, thus starting the inflammatory cascade reaction. Isoflurane anesthesia is reported to increase the incidence of POCD in diabetic rats by a TNF- $\alpha$-dependent mechanism [28].

We found that the plasma concentrations of IL- 6 and TNF- $\alpha$ were significantly higher throughout the first postoperative week in those exposed to sevoflurane than propofol. Furthermore, the plasma concentrations of IL-6 and TNF- $\alpha$ were significantly lower in those undergoing sevoflurane anesthesia if they had been administered methylprednisolone preoperatively. This suggests that the pro-inflammatory cytokines IL- 6 and TNF- $\alpha$ may be part of the mechanism underlying the pathophysiology of POCD in elderly patients undergoing major surgery.

Methylprednisolone $(10 \mathrm{ug} / \mathrm{mL})$ could suppress lymphocyte blastoid transformation, immunoglobulin production, and inflammatory action [29]. This study showed that preoperative methylprednisolone administration suppressed postoperative increases in the plasma levels of IL- 6 and TNF- $\alpha$. Methylprednisolone may be an effective means of reducing the incidence of POCD in elderly patients caused by sevoflurane inhalation anesthesia by suppressing the level of IL- 6 and TNF- $\alpha$.

We found a higher incidence of POCD in patients undergoing major surgery under sevoflurane anesthesia, and an association with increased plasma concentrations of IL- 6 and TNF- $\alpha$. Preoperative treatment with methylprednisolone may afford a degree of protection against POCD, raising the possibility that it could be used prophylactically in elderly patients undergoing major surgery.

\section{Conclusions}

We found that the incidence of POCD was higher in patients undergoing sevoflurane anesthesia for major surgery than those receiving an intravenous propofol regime, and lower in elderly patients pro-treating with methylprednisolone. The MMSE and MoCA were useful tools for the detection of POCD, and plasma S-100 $\beta$ protein concentration may be a useful biomarker of disease. Furthermore, POCD was associated with elevated plasma concentrations of IL- 6 and TNF- $\alpha$.

\section{Abbreviations}

POCD: Postoperative cognitive; MMSE: Mini-mental state examination; MoCA: Montreal cognitive assessment; TNF-a: Tumor necrosis factor-a; IL-6: Interleukin-6; BP: Blood pressure; HR: Heart rate; CVP: Central venous pressure; BIS: Bispectral index; ECG: Electrocardiography; ELISA: Enzyme-linked immunosorbent assay; ANOVA: One-way analysis of variance.

\section{Competing interests}

The authors declare that they have no competing interests.

\section{Authors' contributions}

$Y Q, H F, X Z, H Y, H Z$ and $T Z$ carried out all the experiments, participated in the molecular biology studies, YQ participated in performed the statistical analysis and drafted the manuscript. XZ participated in the design and conceived of the study, and participated in its design and coordination and helped to draft the manuscript. All authors read and approved the final manuscript. 


\section{Acknowledgements}

The authors thank Medical Research Center of the second affiliated Hospital of Shandong University for equipment support and technical assistance.

\section{Author details}

'Department of Anesthesiology, the Second Affiliated Hospital of Shandong University, Ji'nan, Shandong 250033, China. ${ }^{2}$ Department of Anesthesiology, Rizhao People's Hospital, Ri'zhao, 276000 Shandong, China.

\section{Received: 4 March 2015 Accepted: 7 October 2015}

Published online: 23 October 2015

\section{References}

1. Fong HK, Sands LP, Leung JM. The role of postoperative analgesia in delirium and cognitive decline in elderly patients: a systematic review. Anesth Analg. 2006;102(4):1255-66.

2. Rundshagen I. Postoperative cognitive dysfunction. Dtsch Arztebl Int. 2014;111(8):119-25.

3. Moller JT, Cluitmans P, Rasmussen LS, Houx P, Rasmussen H, Canet J, et al. Long-term postoperative cognitive dysfunction in the elderly ISPOCD1 study. ISPOCD investigators. International Study of Post-Operative Cognitive Dysfunction. Lancet. 1998;351(9106):857-61.

4. Monk TG, Weldon BC, Garvan CW, Dede DE, van der Aa MT, Heilman KM, et al. Predictors of cognitive dysfunction after major noncardiac surgery. Anesthesiology. 2008;108(1):18-30.

5. Rossi A, Burkhart C, Dell-Kuster S, Pollock BG, Strebel SP, Monsch AU, et al. Serum anticholinergic activity and postoperative cognitive dysfunction in elderly patients. Anesth Analg. 2014;119(4):947-55.

6. Lili $X$, Zhiyong $H$, Jianjun S. A preliminary study of the effects of ulinastatin on early postoperative cognition function in patients undergoing abdominal surgery. Neurosci Lett. 2013;541:15-9.

7. Li YC, Xi CH, An YF, Dong WH, Zhou M. Perioperative inflammatory response and protein S-100beta concentrations-relationship with post-operative cognitive dysfunction in elderly patients. Acta Anaesthesiol Scand. 2012:56(5):595-600.

8. Cao XZ, Ma H, Wang JK, Liu F, Wu BY, Tian AY, et al. Postoperative cognitive deficits and neuroinflammation in the hippocampus triggered by surgical trauma are exacerbated in aged rats. Prog Neuro-Psychopharmacol Biol Psychiatry. 2010;34(8):1426-32.

9. Benedict C, Cedernaes J, Giedraitis V, Nilsson EK, Hogenkamp PS, Vagesjo E, et al. Acute sleep deprivation increases serum levels of neuron-specific enolase (NSE) and S100 calcium binding protein B (S-100B) in healthy young men. Sleep. 2014;37(1):195-8.

10. Hovens IB, Schoemaker RG, van der Zee EA, Heineman E, Izaks GJ, Van Leeuwen BL. Thinking through postoperative cognitive dysfunction: How to bridge the gap between clinical and pre-clinical perspectives. Brain Behav Immun. 2012;26(7):1169-79.

11. Steinmetz J, Christensen KB, Lund T, Lohse N, Rasmussen LS, Group I. Long-term consequences of postoperative cognitive dysfunction. Anesthesiology. 2009;110(3):548-55.

12. Laalou FZ, Jochum D, Pain L. Postoperative cognitive dysfunction (POCD): strategy of prevention, assessment and management. Ann Fr Anesth Reanim. 2011;30(10):e49-53.

13. Ikonomidou C, Bosch F, Miksa M, Bittigau P, Vockler J, Dikranian K, et al. Blockade of NMDA receptors and apoptotic neurodegeneration in the developing brain. Science. 1999;283(5398):70-4.

14. Loepke AW, Istaphanous GK, McAuliffe 3rd JJ, Miles L, Hughes EA, McCann $J C$, et al. The effects of neonatal isoflurane exposure in mice on brain cell viability, adult behavior, learning, and memory. Anesth Analg. 2009;108(1):90-104.

15. Culley DJ, Loguinov A, Yukhananov R, Crosby G. General anesthesia does not reduce life expectancy in aged rats. Anesth Analg. 2006;102(3):956-9.

16. Uemura $E$, Levin $E D$, Bowman RE. Effects of halothane on synaptogenesis and learning behavior in rats. Exp Neurol. 1985;89(3):520-9.

17. Qin L, Wu X, Block ML, Liu Y, Breese GR, Hong JS, et al. Systemic LPS causes chronic neuroinflammation and progressive neurodegeneration. Glia. 2007;55(5):453-62.

18. Rohan D, Buggy DJ, Crowley S, Ling FK, Gallagher H, Regan C, et al. Increased incidence of postoperative cognitive dysfunction $24 \mathrm{hr}$ after minor surgery in the elderly. Can J Anaesth. 2005;52(2):137-42.
19. Wiesmann M, Missler U, Gottmann D, Gehring S. Plasma S-100b protein concentration in healthy adults is age-and sex-independent. Clin Chem. 1998;44(5):1056-8.

20. Herrmann M, Curio N, Jost S, Wunderlich MT, Synowitz H, Wallesch CW. Protein S-100B and neuron specific enolase as early neurobiochemical markers of the severity of traumatic brain injury. Restor Neurol Neurosci. 1999;14(2-3):109-14.

21. Linstedt U, Meyer O, Kropp P, Berkau A, Tapp E, Zenz M. Serum concentration of S-100 protein in assessment of cognitive dysfunction after general anesthesia in different types of surgery. Acta Anaesthesiol Scand. 2002:46(4):384-9.

22. Milligan ED, Sloane EM, Langer SJ, Cruz PE, Chacur M, Spataro L, et al. Controlling neuropathic pain by adeno-associated virus driven production of the anti-inflammatory cytokine, interleukin-10. Mol Pain. 2005;1:9.

23. Richwine AF, Parkin AO, Buchanan JB, Chen J, Markham JA, Juraska JM, et al. Architectural changes to CA1 pyramidal neurons in adult and aged mice after peripheral immune stimulation. Psychoneuroendocrinology. 2008;33(10):1369-77.

24. Vallieres L, Campbell IL, Gage FH, Sawchenko PE. Reduced hippocampal neurogenesis in adult transgenic mice with chronic astrocytic production of interleukin-6. J Neurosci. 2002;22(2):486-92.

25. Balschun D, Wetzel W, Del Rey A, Pitossi F, Schneider H, Zuschratter W, et al. Interleukin-6: a cytokine to forget. FASEB J. 2004;18(14):1788-90.

26. Wan Y, Xu J, Ma D, Zeng Y, Cibelli M, Maze M. Postoperative impairment of cognitive function in rats: a possible role for cytokine-mediated inflammation in the hippocampus. Anesthesiology. 2007;106(3):436-43.

27. Hudetz JA, Gandhi SD, labal Z, Patterson KM, Pagel PS. Elevated postoperative inflammatory biomarkers are associated with short-and medium-term cognitive dysfunction after coronary artery surgery. J Anesth. 2011;25(1):1-9.

28. Yang C, Zhu B, Ding J, Wang ZG. Isoflurane anesthesia aggravates cognitive impairment in streptozotocin-induced diabetic rats. Int J Clin Exp Med. 2014;7(4):903-10.

29. Webel ML, Ritts Jr RE, Taswell HF, Danadio Jr JV, Woods JE. Cellular immunity after intravenous administration of methylprednisolone. J Lab Clin Med. 1974;83(3):383-92.

\section{Submit your next manuscript to BioMed Central and take full advantage of:}

- Convenient online submission

- Thorough peer review

- No space constraints or color figure charges

- Immediate publication on acceptance

- Inclusion in PubMed, CAS, Scopus and Google Scholar

- Research which is freely available for redistribution 